\title{
Performance Evaluation of Balanced Pension Plans
}

\author{
Laura Andreu, and Laurens Swinkels
}

\begin{tabular}{|l|l|}
\hline \multicolumn{2}{|l|}{ ERIM REPORT SERIES RESEARCH IN MANAGEMENT } \\
\hline ERIM Report Series reference number & ERS-2010-037-F\&A \\
\hline Publication & October 2009 \\
\hline Number of pages & 32 \\
\hline Persistent paper URL & \\
\hline Email address corresponding author & Iswinkels@ese.eur.nl \\
\hline Address & Erasmus Research Institute of Management (ERIM) \\
& RSM Erasmus University / Erasmus School of Economics \\
& Erasmus Universiteit Rotterdam \\
& P.O.Box 1738 \\
& 3000 DR Rotterdam, The Netherlands \\
& Phone: + 31 10 408 1182 \\
& Fax: + 31104089640 \\
& Email: info@erim.eur.nl \\
& Internet: $\quad$ www.erim.eur.nl \\
\hline
\end{tabular}

Bibliographic data and classifications of all the ERIM reports are also available on the ERIM website: www.erim.eur.nl 


\section{ERASMUS RESEARCH INSTITUTE OF MANAGEMENT}

\section{REPORT SERIES}

\section{RESEARCH IN MANAGEMENT}

\begin{tabular}{|l|l|}
\hline ABSTRACT AND KEYWORDS \\
\hline Abstract & $\begin{array}{l}\text { This paper examines the ability of balanced pension plan managers to successfully time the } \\
\text { equity and bond market and select the appropriate assets within these markets. In order to } \\
\text { evaluate both market timing abilities in these balanced pension plans, we extend the traditional } \\
\text { equity market timing models to also account for bond market timing. As far as we know, we are } \\
\text { among the first to apply this multifactor timing model to investigate equity and bond market } \\
\text { timing simultaneously. This performance evaluation has been conducted on two samples of } \\
\text { Spanish balanced pension plans, one with Euro Zone and one with World investment focus. This } \\
\text { allows us to decompose managers' skills in three components: selectivity, equity market timing, } \\
\text { and bond market timing. Our findings suggest that the average stock picking ability of pension } \\
\text { plans is positive. World schemes tend to have positive bond timing skills, while Euro Zone } \\
\text { pension plans are on average not able to time equity or bond markets. }\end{array}$ \\
\hline Free Keywords & balanced pension plans, market timing, performance evaluation, stock picking \\
\hline Availability & $\begin{array}{l}\text { The ERIM Report Series is distributed through the following platforms: } \\
\text { Academic Repository at Erasmus University (DEAR), DEAR ERIM Series Portal } \\
\text { Social Science Research Network (SSRN), SSRN ERIM Series Webpage } \\
\text { Research Papers in Economics (REPEC), REPEC ERIM Series Webpage }\end{array}$ \\
\hline Classifications & $\begin{array}{l}\text { The electronic versions of the papers in the ERIM report Series contain bibliographic metadata } \\
\text { by the following classification systems: } \\
\text { Library of Congress Classification, (LCC) LCC Webpage } \\
\text { Journal of Economic Literature, (JEL), JEL Webpage } \\
\text { ACM Computing Classification System CCS Webpage } \\
\text { Inspec Classification scheme (ICS), ICS Webpage }\end{array}$ \\
\hline
\end{tabular}




\title{
Performance Evaluation of Balanced Pension Plans ${ }^{1}$
}

\author{
Laura Andreu \\ University of Zaragoza \\ landreu@unizar.es \\ Laurens Swinkels \\ Erasmus Research Institute of Management \\ Robeco Quantitative Strategies \\ Iswinkels@few.eur.nl
}

October 2009

\footnotetext{
${ }^{1}$ We would like to thank José Luis Sarto for valuable comments and DGA (CONAID) and CAI for the funds provided through the research programme CAI Europe. Large part of this paper was written when Laura Andreu was visiting Erasmus School of Economics in Rotterdam. The views expressed in this paper do not necessarily represent those of Robeco or any of its subsidiaries.
} 


\title{
Performance Evaluation of Balanced Pension Plans
}

\begin{abstract}
:
This paper examines the ability of balanced pension plan managers to successfully time the equity and bond market and select the appropriate assets within these markets. In order to evaluate both market timing abilities in these balanced pension plans, we extend the traditional equity market timing models to also account for bond market timing. As far as we know, we are among the first to apply this multifactor timing model to investigate equity and bond market timing simultaneously. This performance evaluation has been conducted on two samples of Spanish balanced pension plans, one with Euro Zone and one with World investment focus. This allows us to decompose managers' skills in three components: selectivity, equity market timing, and bond market timing. Our findings suggest that the average stock picking ability of pension plans is positive. World schemes tend to have positive bond timing skills, while Euro Zone pension plans are on average not able to time equity or bond markets.
\end{abstract}

Key words: Balanced Pension Plans, Market Timing, Performance Evaluation, Stockpicking.

JEL Code: G11 


\section{INTRODUCTION}

The investment performance of the portfolios is often measured by their average return over a certain holding period. Although these average returns can be quite dispersed, it is not always clear what causes these differences. This dispersion is usually attributed to the good actions taken by managers. These decisions can either derive from the manager's ability to choose securities, selectivity or stock-picking skill (alpha) or from the prediction ability about the market returns, market timing skill (beta) ${ }^{2}$.

Managers can actively decide to alter the exposure to the market according to the publicly available information or to their personal expectations about future market returns. In that way, investors could benefit from active allocation towards bull markets and away from declining markets. Therefore, information about the dynamics of the portfolio's market exposure as well as the associated additional expected return is very valuable for individual investors.

The literature on market timing focuses mostly on equity mutual funds. ${ }^{3}$ As a consequence, the traditional timing models analyse funds as if they are composed of only stocks and Treasury bills and evaluate the performance by focusing on the choice between stocks and cash and ignoring the part of the portfolio invested in bonds. This holding in bonds can be significant for some types of mutual funds such as fixed-

\footnotetext{
${ }^{2}$ Some authors such as Brinson et al. (1986) and Brinson et al. (1991) also state that a high proportion of the variability of the returns obtained by the portfolios over time is determined by the variation of the strategic policy.

${ }^{3}$ Most of the empirical evidence suggests that fund managers are not capable to time the equity market; see, e. g., Treynor and Mazuy (1966) and Ferson and Schadt (1996), among others. A notable exception is the study carried out by Bollen and Busse (2001), who find positive market timing based on daily information. Wermers (2000), Glassman and Riddick (2006) and Jiang et al. (2007) also find timing ability analysing portfolio composition. More recently, Swinkels and Tjong-A-Tjoe (2007) strength the evidence of Bollen and Busse (2001) in favour of market timing by analysing not only market timing but style timing abilities on size, valuation and momentum.
} 
income funds and hybrid funds. However, little is known about the manager skills of these portfolios.

Comer (2006) and Rodriguez (2008) use a multifactor extension of Treynor and Mazuy (1966) model to examine both equity and bond timing skills. They focus their attention on improving the measurement of the timing ability of hybrid mutual funds by comparing the results of the stock market timing coefficients of the traditional model and those obtained by a multifactor model that includes bond indices and a quadratic bond term. Specifically, the abovementioned studies find that the inclusion of bond indices and bond timing variables in the model leads to different conclusions about the stock market timing performance. However, they do not investigate bond market timing ability as a separate source of investment performance. We feel this could be an important performance driver and analyse this in more detail.

This lack of empirical studies analysing the timing ability on balanced funds leads us to focus on improving the measurement of the timing abilities of these portfolios. In addition, we must highlight that over the last 10 years, there has been an important growth in the number of Spanish balanced pension plans. Over 80 equity balanced plans were in existence in 1998 while the number has grown to almost 200 in 2008. The number of investors and the asset under management by balanced pension plans has also experienced a considerable increased $(3.35 \%$ and $2.76 \%$, respectively).

Therefore, we contribute to this line of research by investigating the equity and bond market timing of Spanish balanced pension plans by applying a novel multifactor performance evaluation model. In addition, our results provide out-ofsample evidence for conclusions drawn on the U.S. hybrid mutual fund market. 
There are some studies that have investigated the existence of the market timing ability by analysing Spanish mutual funds. Specifically, the studies conducted by Ferruz et al. (2006) and Ferruz and Vargas (2007) conclude the absence of equity market timing ability of Spanish mutual fund managers. Matallin (2006) describes the importance of the right benchmarks when investigating market timing skills for Spanish mutual funds. ${ }^{4}$ Finally, Doncel et al (2009) investigate long run persistence in Spanish equity, balanced, and bond mutual funds. In spite of previous studies of Spanish mutual funds, there is a lack of empirical evidence about the performance of Spanish pension plans. Thus, our paper aims to extend this strand of literature to investigate the performance of balanced pension plans in Spain.

The main purpose of this paper is to fill this gap of empirical conclusions about the investment skills of balanced pension plan managers using a novel performance attribution framework. In particular, we analyse the abilities of Spanish balanced pension plan managers. Given that these investment vehicles hold mainly a combination of stocks, bonds and cash in their portfolios, traditional market timing models are not suitable. For that reason, the main contribution of this paper is the measurement of the equity and bond market timing in balanced portfolios, a scarcely explored investment vocation. This issue is addressed by estimating the timing coefficients from a multifactor version of the Treynor and Mazuy (1966) model. ${ }^{5}$ As Comer (2006) stresses, the empirical literature has not fully exploited multifactor timing model methodologies when it comes to examining balanced portfolios. Our research can be seen as an extension of the existing timing model and out-of-sample

\footnotetext{
${ }^{4}$ Other effects that could hamper fund performance, such as liquidity needs, are discussed in this paper. See also, e. g., Warther (1995), Edelen (1999) and Pástor and Stambaugh (2002), among others.

${ }^{5}$ Note that this multifactor model is similar to that applied in Comer (2006) and Rodriguez (2008).
} 
evidence of the use of this type of multifactor timing models for the U.S. hybrid mutual fund market.

Finally, it is important to emphasize the relevance of this line of research for various reasons. From an academic perspective, appropriate measuring of the timing ability may have implications for the efficient market hypothesis. On the other hand, from an investor's perspective, identifying superior managers is an important objective. Concretely, the results obtained by Boney et al. (2009) when analysing the timing of bond funds confirm that, in spite of the perverse timing ability between cash and bonds and across bonds of various maturities, investors value funds for the diversification benefits they provide within the investors' overall portfolio. On the other hand, the timing abilities could influence on how investors assign their savings among the different investment vehicles available and consequently, it could encourage the investment in private pension schemes.

Our findings suggest that pension plans are on average not able to add value by timing equity or bond markets. The majority of Euro Zone and World pension plans show negative equity market timing skills. The Euro Zone pension plans seem to have negative bond market skill as well, whereas World pension plans show slightly positive bond market timing skill. The stock picking ability of pension plans is on average positive with $1.09 \%$ per year for Euro Zone pension plans and $1.81 \%$ per year for World pension plans. However, these are gross return figures and once management fees are subtracted, the selectivity skill is reduced to zero as well.

The remainder of the paper is organised as follows. Section 2 provides a description of the Spanish pension market along with the data used in our research. Section 3 describes the performance evaluation models and the empirical results obtained. Finally, conclusions are drawn in Section 4. 


\section{DESCRIPTION OF THE SPANISH PENSION MARKET AND DATA}

\subsection{The Spanish pension market}

The Spanish pension system is structured in three pillars, as in the majority of the European countries. In this sense, the first two pillars are administered by the State on a pay-as-you go $(P A Y G)$ basis whereas the third pillar is a voluntary funded system that gathers occupational and personal pension schemes.

In December 2007, almost $€ 86,600$ million of more than 10 million of investors were invested in private pension schemes, representing more than $6 \%$ of the Spanish family savings. Our research focuses on personal pension plans, since these are much more important than occupational pension plans in the Spanish market. At the end of 2007, personal pension plans represent more than $62 \%$ of the assets under management and more than $80 \%$ of investors. This feature contrasts with other pension industries like the U.K and The Netherlands, where occupational pension plans are the most important category.

\subsection{Fund sample}

More specifically, our focus lies on the performance evaluation of Spanish balanced personal pension plans given that these plans are more likely to establish market timing by changing their market exposures due to their flexible investment goal. In particular, we analyse all Spanish balanced personal pension plans that invest in Euro Zone and World equities over the period April 2000 to December 2007 according to the Spanish Association of Collective Investment and Pension Funds (Inverco). In order to be classified as a balanced pension scheme, the portfolios must be committed to maintaining between $30 \%$ and $75 \%$ of their assets in equities according to the 
classifications provided by Inverco. Monthly returns of Spanish balanced pension plans are obtained from Inverco database.

Our final two samples include 94 and 45 portfolios, respectively. The only requirement for a pension plan to be included in the study is that the plan survives for a minimum of three years as a balanced pension scheme. ${ }^{6}$ Once the three-year criterion is attained, the dataset does not suffer from survivorship bias since it gathers every pension plan commercialised in Spain during that period. It should be noted that although neither pension plan sample is subject to survivorship bias, both potentially suffer from look-ahead bias. In fact, as mentioned by Comer (2006) and Boney et al. (2009) among others, some look-ahead bias is inherent in tests of market timing ability where a minimum survival period is necessary to obtain robust estimations.

Table 1 provides descriptive statistics of the balanced pension plans analysed. ${ }^{7}$ Specifically, the table list a random number assigned to each pension plan and the range of reported portfolio weights reported over the time period analysed (20002007). These weights are based on annual pension fund reports by the Spanish Association of Collective Investment and Pension Funds (Inverco). From this table, we can conclude that asset allocation between equity markets, bonds, and cash play an important role in the portfolios of Spanish balanced pension plans. This requires us to use methods beyond the traditional performance evaluation models in order to correctly analyse the manager skill. ${ }^{8}$

\footnotetext{
${ }^{6}$ We have excluded one portfolio classified as Euro Zone balanced by the Spanish Association of Collective Investment and Pension Funds since its information does not conform to this category. On the other hand, only 21 and 32 balanced plans investing in Euro Zone and World equities do not fulfil the three-year period required to be included in our samples.

${ }^{7}$ Note that, the portfolio weights invested in some pension plans are identical given that weights reported in Table 1 correspond to the pension funds in which the plans are included. Pension funds can encompass several pension plans of different investment vocations. For that reason, the equity weights of some portfolios do not reach the minimum exposure to equities established by Inverco.

${ }^{8}$ The active management of pension funds is also stated in their investment policies. For example, Fund 11 from the sample of World Funds states: "The portfolio invest in equity assets with the aim of
} 


\subsection{Index data}

For the implementation of market timing models, data on several market indices is also needed. In this respect, using data from Morgan Stanley Capital InternationalBarra and the Bank of Spain ${ }^{9}$, we have collected information about the monthly returns of a set of benchmarks that represent the main holdings in equities and fixedincome assets of Spanish balanced portfolios. In order to determine in which benchmarks our portfolios are heavily invested, we have followed the return-based style analysis proposed by Sharpe (1992).

Bearing in mind the requirements established by Sharpe's method about the exhaustiveness, exclusiveness and independence of the indices and based on the study of Andreu et al. $(2008)^{10}$, we have considered the MSCI EMU Gross Return index and the MSCI World Gross Return index as benchmarks representative of the equity holding in each sample ${ }^{11}$, 5-year Spanish Government Debt as benchmark representative of fixed-income and 1-day Spanish Treasury Bill Repos as benchmark representative of cash.

having a central exposure of $60 \%$ and a maximum of $75 \%$ in World equity assets being the portfolio actively managed according to market expectations."

${ }^{9} \mathrm{See} h \mathrm{htp}: / / \mathrm{www} . \mathrm{mscibarra.com/} \mathrm{for} \mathrm{equity} \mathrm{benchmark} \mathrm{information} \mathrm{and} \mathrm{http://www.bde.es/} \mathrm{for} \mathrm{fixed-}$ income and cash indexes.

${ }_{10}$ This paper analyses the asset allocation of Spanish equity pension plans considering only two benchmarks, the equity and cash index. However, given that we analyse balanced portfolios it is absolutely necessary to define another benchmark representative of the bond holding. In this sense, we have examined different benchmarks with different maturities, finding that the portfolios analysed are heavily invested in Public Debt with a maturity of 5 years.

${ }^{11}$ Both indices are denominated in Euro Currency. 
Table 1 Sample of Spanish Balanced Pension Plans

\begin{tabular}{|c|c|c|c|c|c|c|c|c|c|c|}
\hline Panel A & & ocks & Bonds & Cash & & & ocks & Bonds & & Cash \\
\hline 1 & 26.20 & -56.40 & $5.99-30.77$ & $12.80-63.20$ & 48 & 41.10 & -58.70 & $17.31-41.43$ & 3.79 & -28.30 \\
\hline 2 & 30.96 & - 40.55 & $45.62-48.19$ & $10.70-19.10$ & 49 & 26.20 & -56.40 & $5.99-30.77$ & 12.80 & -63.20 \\
\hline 3 & 26.20 & - 56.40 & $5.99-30.77$ & $12.80-63.20$ & $\mathbf{5 0}$ & 26.20 & -56.40 & $5.99-30.77$ & 12.80 & -63.20 \\
\hline 4 & 43.45 & - 54.30 & $11.42-32.63$ & $11.60-37.50$ & 51 & 40.67 & -49.32 & $42.42-53.98$ & 3.63 & -13.00 \\
\hline 5 & 16.33 & - 49.40 & $34.70-43.19$ & $10.60-40.70$ & 52 & 63.42 & -73.63 & $18.91-33.04$ & 3.51 & -15.50 \\
\hline 6 & 16.33 & - 49.40 & $34.70-43.19$ & $10.60-40.70$ & 53 & 21.71 & -50.40 & $25.22-40.50$ & 6.30 & -50.00 \\
\hline 7 & 43.45 & - 54.30 & $11.42-32.63$ & $11.60-37.50$ & 54 & 62.40 & -72.80 & $13.60-19.34$ & 5.45 & -17.80 \\
\hline 8 & 21.60 & - 35.10 & $37.78-55.42$ & $9.61-36.10$ & 55 & 16.33 & -49.40 & $34.70-43.19$ & 10.60 & -40.70 \\
\hline 9 & 18.62 & - 25.35 & $53.70-69.30$ & $7.42-14.50$ & 56 & 41.23 & -70.50 & $11.02-37.53$ & 7.69 & -19.40 \\
\hline 10 & 26.20 & - 49.80 & $5.99-26.32$ & $28.50-63.20$ & 57 & 46.70 & -69.80 & $16.57-26.96$ & 10.60 & -21.40 \\
\hline 11 & 38.65 & - 70.00 & $4.78-37.53$ & $12.10-51.60$ & 58 & 28.36 & -37.68 & $41.42-67.50$ & 0.82 & -26.50 \\
\hline 12 & 28.36 & - 37.60 & $41.42-67.50$ & $0.82-26.50$ & 59 & 8.24 & -22.50 & $16.49-69.00$ & 8.44 & -91.40 \\
\hline 13 & 26.20 & - 56.40 & $5.99-30.77$ & $12.80-63.20$ & 60 & 21.60 & -35.10 & $37.78-55.42$ & 9.61 & -36.10 \\
\hline 14 & 21.60 & - 35.10 & $37.78-55.42$ & $9.61-36.10$ & 61 & 41.10 & -71.90 & $23.51-38.40$ & 8.29 & -16.80 \\
\hline 15 & 24.21 & - 41.54 & $32.50-38.50$ & $18.90-39.90$ & 62 & 21.60 & -35.00 & $37.78-53.42$ & 16.80 & -36.10 \\
\hline 16 & 24.21 & - 41.54 & $32.50-38.50$ & $18.90-39.90$ & 63 & 26.20 & -62.70 & $5.99-37.44$ & 3.51 & -63.20 \\
\hline 17 & 53.50 & - 73.00 & $15.80-36.75$ & $4.20-7.55$ & 64 & 11.52 & -51.31 & $39.37-49.20$ & 2.21 & -14.70 \\
\hline 18 & 37.74 & - 73.70 & $22.58-50.74$ & $1.64-11.50$ & 65 & 37.11 & -54.70 & $32.20-47.42$ & 5.59 & -11.50 \\
\hline 19 & 22.79 & - 44.81 & $1.54-21.34$ & $32.90-77.80$ & 66 & 55.66 & -75.61 & $20.55-24$ & 3.58 & -18.70 \\
\hline 20 & & - 86.40 & $5.63-24.73$ & $4.76-23.10$ & 67 & & & & 9.61 & \\
\hline 21 & 24.65 & - 89.50 & & $9.46-71.90$ & 68 & 26.20 & -56.40 & $5.99-30.77$ & 12.80 & -63.20 \\
\hline 22 & 48.80 & - 62.60 & $19.91-47.30$ & $0.22-19.00$ & 69 & \multicolumn{5}{|c|}{ No annual weights reported } \\
\hline 23 & 44.55 & - 60.00 & $22.50-30.40$ & $9.15-28.10$ & 70 & 53.70 & -67.10 & $38.86-48.57$ & 0.60 & -6.71 \\
\hline 24 & 24.80 & - 69.70 & $18.60-61.50$ & $12.10-13.40$ & 71 & 18.62 & -25.35 & $53.70-69.30$ & 7.42 & -14.50 \\
\hline 25 & \multicolumn{4}{|c|}{ No annual weights reported } & 72 & 18.62 & -25.35 & $53.70-69.30$ & 7.42 & -14.50 \\
\hline 26 & 26.20 & - 49.80 & $5.99-26.32$ & $28.50-63.20$ & 73 & \multicolumn{5}{|c|}{ No annual weights reported } \\
\hline 27 & 42.69 & - 44.27 & $42.30-50.00$ & $5.81-13.40$ & 74 & 52.20 & & $9.88-34.42$ & 3.89 & -19.52 \\
\hline 28 & 42.60 & - 79.60 & $36.55-47.05$ & $8.51-20.60$ & 75 & 52.51 & -66.70 & $9.09-9.09$ & 36.40 & -38.90 \\
\hline 29 & 44.20 & - 73.70 & $9.86-17.45$ & $10.90-19.60$ & 76 & 38.42 & -67.70 & $8.59-34.30$ & 7.23 & -16.90 \\
\hline 30 & 39.40 & - 59.10 & $3.55-19.93$ & $14.20-42.00$ & 77 & 15.50 & -40.20 & $23.84-56.32$ & 3.33 & -35.10 \\
\hline 31 & 42.80 & - 66.60 & $28.30-40.70$ & $1.35-18.00$ & 78 & 24.21 & -41.54 & $32.50-38.50$ & 18.90 & -39.90 \\
\hline 32 & 18.60 & - 30.80 & $35.56-69.40$ & $2.48-37.20$ & 79 & 43.10 & -71.90 & $30.04-42$ & 4.12 & -19.20 \\
\hline 33 & 59.10 & - 63.50 & $21.60-36.83$ & $4.61-14.80$ & 80 & 49.18 & -72.10 & $1.33-19.40$ & 3.75 & -9.86 \\
\hline 34 & 9.07 & - 21.11 & $4.88-73.30$ & $17.50-95.80$ & 81 & \multicolumn{5}{|c|}{ No annual weights reported } \\
\hline 35 & 50.20 & - 63.30 & $32.61-37.00$ & $4.05-8.55$ & 82 & 38.80 & -38.96 & $20.35-23.30$ & 15.40 & -19.10 \\
\hline 36 & 14.99 & - 39.00 & $5.99-41.26$ & $35.50-65.80$ & 83 & 26.20 & -56.40 & $5.99-30.77$ & 12.80 & -63.20 \\
\hline 37 & 21.60 & - 35.10 & $37.78-55.42$ & $9.61-36.10$ & 84 & 21.60 & -35.10 & $37.78-55.42$ & 9.61 & -36.10 \\
\hline 38 & 26.20 & - 56.40 & $5.99-30.77$ & $12.80-63.20$ & 85 & 26.20 & -56.40 & $5.99-30.77$ & 12.80 & -63.20 \\
\hline 39 & 26.20 & - 56.40 & $5.99-30.77$ & $12.80-63.20$ & 86 & 54.30 & -63.80 & $32.75-33.96$ & 3.00 & -7.70 \\
\hline 40 & 26.20 & - 63.60 & $5.99-33.36$ & $10.80-63.20$ & 87 & 21.60 & -35.10 & $37.78-55.42$ & 9.61 & -36.10 \\
\hline 41 & 21.60 & - 35.10 & $37.78-55.42$ & $9.61-36.10$ & 88 & 26.20 & -56.40 & $5.99-30.77$ & 12.80 & -63.20 \\
\hline 42 & 26.30 & - 35.10 & $44.70-55.42$ & $9.61-28.00$ & 89 & \multicolumn{5}{|c|}{ No annual weights reported } \\
\hline 43 & 26.20 & - 56.40 & $5.99-30.77$ & $12.80-63.20$ & 90 & 30.96 & -40.55 & $45.62-48.19$ & 10.70 & -19.10 \\
\hline 44 & 37.20 & - 48.10 & - & $51.80-62.70$ & 91 & 32.29 & -32.83 & $41.70-44.90$ & 21.00 & -24.10 \\
\hline 45 & 21.60 & - 35.10 & $37.78-55.42$ & $9.61-36.10$ & 92 & \multicolumn{5}{|c|}{ No annual weights reported } \\
\hline 46 & 29.28 & - 38.50 & $51.00-51.30$ & $10.40-18.00$ & 93 & \multicolumn{5}{|c|}{ No annual weights reported } \\
\hline 47 & 37.90 & -53.00 & $25.72-34.70$ & $9.26-28.70$ & 94 & 47.90 & -97.20 & $19.19-47.61$ & 4.91 & -23.70 \\
\hline
\end{tabular}




\section{Continued}

\begin{tabular}{|c|c|c|c|c|c|c|c|c|c|c|c|c|}
\hline \multirow{2}{*}{$\frac{\text { Panel B }}{1}$} & \multicolumn{2}{|c|}{ Stocks } & \multicolumn{2}{|c|}{ Bonds } & \multicolumn{2}{|c|}{ Cash } & \multicolumn{3}{|c|}{ Stocks } & Bonds & \multicolumn{2}{|c|}{ Cash } \\
\hline & 10.60 & - 58.60 & 15.16 & -72.20 & 5.69 & -52.20 & 24 & 39.55 & -63.18 & $31.09-52.71$ & 0.10 & - 16.20 \\
\hline 2 & 25.40 & - 84.30 & 19.90 & - 55.42 & 9.61 & -55.70 & 25 & 13.88 & -31.80 & $25.19-54.94$ & 15.70 & - 41.30 \\
\hline 3 & 53.10 & - 90.50 & 1.28 & - 24.03 & 7.44 & -40.00 & 26 & 41.23 & - 57.10 & $22.76-37.53$ & 12.10 & - 19.40 \\
\hline 4 & 10.60 & - 58.60 & 15.16 & -72.20 & 5.69 & -52.20 & 27 & 53.10 & -90.50 & $1.28-30.77$ & 10.80 & - 40.00 \\
\hline 5 & 41.23 & -70.50 & 11.02 & -37.53 & 7.69 & - 19.40 & 28 & 25.40 & - 84.30 & $19.90-49.60$ & 17.40 & - 55.70 \\
\hline 6 & 37.74 & - 73.70 & 22.58 & - 50.74 & 1.64 & -11.50 & 29 & 53.10 & - 90.50 & $1.28-18.50$ & 10.80 & -40.00 \\
\hline 7 & 10.60 & - 58.60 & 23.08 & -72.20 & 5.69 & -52.20 & 30 & 25.40 & -84.30 & $3.97-49.60$ & 17.40 & - 55.70 \\
\hline 8 & 25.40 & - 37.90 & 20.70 & -46.96 & 16.30 & -51.70 & 31 & \multicolumn{5}{|c|}{ No annual weights reported } \\
\hline 9 & 25.40 & - 37.90 & 20.70 & -46.96 & 16.30 & -51.70 & 32 & 41.40 & -56.95 & $42.01-53.87$ & 0.54 & 6.72 \\
\hline 10 & 25.40 & - 37.90 & 20.70 & -46.96 & 16.30 & -51.70 & 33 & 25.04 & -30.00 & $39.60-60.10$ & 4.46 & -28.70 \\
\hline 11 & 35.20 & -60.80 & 14.60 & -29.40 & 11.80 & -44.80 & 34 & 13.88 & - 31.80 & $25.19-54.94$ & 15.70 & -41.30 \\
\hline 12 & 35.20 & -60.80 & 14.60 & -29.40 & 11.80 & -44.80 & 35 & 27.15 & -63.31 & $18.82-58.70$ & 12.50 & -23.00 \\
\hline 13 & 35.20 & - 60.80 & 14.60 & -29.40 & 11.80 & -44.80 & 36 & 27.15 & -54.60 & $24.28-58.70$ & 12.50 & -23.00 \\
\hline 14 & 47.40 & - 68.20 & 13.62 & - 87.20 & 6.28 & -82.50 & 37 & 51.39 & - 89.37 & $1.03-42.08$ & 0.90 & -16.50 \\
\hline 15 & 45.10 & - 53.20 & 33.42 & - 41.04 & 9.46 & -22.30 & 38 & 27.15 & - 63.31 & $18.82-58.70$ & 12.50 & - 23.00 \\
\hline 16 & 33.89 & - 48.90 & 32.63 & -46.60 & 4.40 & -24.30 & 39 & 56.10 & -64.70 & $5.76-33.35$ & 8.82 & - 27.50 \\
\hline 17 & 10.60 & - 58.60 & 23.08 & -72.20 & 5.69 & - 7.66 & 40 & 25.40 & -84.30 & $3.97-49.60$ & 17.40 & - 55.70 \\
\hline 18 & 27.15 & - 63.31 & 18.82 & -58.70 & 12.50 & -23.00 & 41 & 53.10 & -90.50 & $1.28-18.50$ & 10.80 & -40.00 \\
\hline 19 & 35.20 & - 57.90 & 14.60 & - 29.40 & 11.80 & -44.80 & 42 & 25.40 & -84.30 & $3.97-49.60$ & 17.40 & - 39.00 \\
\hline 20 & 61.30 & - 64.30 & 15.05 & -32.13 & 5.26 & -22.10 & 43 & 35.20 & - 57.90 & $14.60-29.40$ & 11.80 & -44.80 \\
\hline 21 & 40.28 & - 55.40 & 18.65 & - 40.44 & 8.23 & -30.30 & 44 & 44.55 & -60.00 & $22.50-30.40$ & 9.15 & - 28.10 \\
\hline 22 & 32.19 & - 66.90 & 5.98 & -23.08 & 13.50 & - 41.90 & 45 & 53.90 & - 69.10 & $16.33-39.90$ & 0.09 & -25.50 \\
\hline 23 & 56.10 & - 64.70 & 5.76 & -33.35 & 8.82 & -27.50 & & & & & & \\
\hline
\end{tabular}

Table 2 provides descriptive statistics of the gross returns and volatility (standard deviation) of the pension plans and benchmarks used in the study. From this table we can detect some differences between the sample of Spanish balanced pension plans that invest in Euro Zone equities and those investing in World equities. In particular, we can observe that for the entire sample period the Spanish pension plans investing in Euro Zone underperform the market. The equally-weighted portfolio has an annual gross return of $2.99 \%$ compared to the equity, fixed-income and cash benchmark returns of $3.32 \%, 4.95 \%$ and $3.11 \%$, respectively. However, the World equally-weighted portfolio outperforms the equity market. 
Table 2. Summary of descriptive statistics

We present some descriptive statistics for our samples of 94 and 45 Spanish balanced pension plans investing in Euro Zone and World equities and for the benchmarks used. These data is reported considering the entire sample period April 2000 to December 2007 and two different periods that run from April 2000 to December 2003 and from January 2004 to December 2007, respectively. The average gross return and volatility (standard deviation) are annualized whereas the minimum and maximum returns are monthly returns. To calculate the average value of each variable, first the mean of the time series of each plan was computed and then the cross-sectional mean was calculated.

\begin{tabular}{lccccc}
\hline \multicolumn{1}{c}{ Pension Plans } & & Average & Minimum & Maximum & Volatility \\
\hline Euro Zone Pension Plans & & & & & \\
Equally-Weighted Portfolio & $(2000 / 4-2007 / 12)$ & $2.99 \%$ & $-6.95 \%$ & $5.64 \%$ & $8.24 \%$ \\
Equally-Weighted Portfolio & $(2000 / 4-2003 / 12)$ & $-4.37 \%$ & $-6.95 \%$ & $5.64 \%$ & $10.21 \%$ \\
Equally-Weighted Portfolio & $(2004 / 1-2007 / 12)$ & $10.37 \%$ & $-2.31 \%$ & $3.34 \%$ & $5.18 \%$ \\
\hline \hline World Pension Plans & & & & & \\
Equally-Weighted Portfolio & $(2000 / 4-2007 / 12)$ & $2.03 \%$ & $-5.59 \%$ & $3.41 \%$ & $7.31 \%$ \\
Equally-Weighted Portfolio & $(2000 / 4-2003 / 12)$ & $-5.01 \%$ & $-5.59 \%$ & $3.41 \%$ & $8.84 \%$ \\
Equally-Weighted Portfolio & $(2004 / 1-2007 / 12)$ & $9.06 \%$ & $-3.22 \%$ & $3.21 \%$ & $4.85 \%$ \\
\hline \multicolumn{1}{c}{ Benchmarks } & & Average & Minimum & Maximum & Volatility \\
\hline MSCI Emu & $(2000 / 4-2007 / 12)$ & $3.32 \%$ & $-17.53 \%$ & $13.82 \%$ & $17.26 \%$ \\
MSCI Emu & $(2000 / 4-2003 / 12)$ & $-10.50 \%$ & $-17.53 \%$ & $13.82 \%$ & $22.34 \%$ \\
MSCI Emu & $(2004 / 1-2007 / 12)$ & $18.02 \%$ & $-4.49 \%$ & $5.96 \%$ & $9.19 \%$ \\
\hline \hline MSCI World & $(2000 / 4-2007 / 12)$ & $-1.03 \%$ & $-11.66 \%$ & $7.66 \%$ & $14.58 \%$ \\
MSCI World & $(2000 / 4-2003 / 12)$ & $-11.69 \%$ & $-11.66 \%$ & $7.66 \%$ & $18.74 \%$ \\
MSCI World & $(2004 / 1-2007 / 12)$ & $10.02 \%$ & $-5.42 \%$ & $6.49 \%$ & $8.23 \%$ \\
\hline \hline 5-Year Spanish Government Debt & $(2000 / 4-2007 / 12)$ & $4.95 \%$ & $-1.47 \%$ & $1.99 \%$ & $2.70 \%$ \\
5-Year Spanish Government Debt & $(2000 / 4-2003 / 12)$ & $6.72 \%$ & $-1.47 \%$ & $1.99 \%$ & $3.11 \%$ \\
5-Year Spanish Government Debt & $(2004 / 1-2007 / 12)$ & $3.31 \%$ & $-0.94 \%$ & $1.39 \%$ & $2.20 \%$ \\
\hline \hline 1-day Spanish Treasury Bill Repos & $(2000 / 4-2007 / 12)$ & $3.11 \%$ & $0.15 \%$ & $0.44 \%$ & $0.28 \%$ \\
1-day Spanish Treasury Bill Repos & $(2000 / 4-2003 / 12)$ & $3.57 \%$ & $0.15 \%$ & $0.44 \%$ & $0.28 \%$ \\
1-day Spanish Treasury Bill Repos & $(2004 / 1-2007 / 12)$ & $2.68 \%$ & $0.15 \%$ & $0.36 \%$ & $0.22 \%$ \\
\hline
\end{tabular}

Table 2 also shows that the first half of the time period is a bear market, being the mean return of the equity market of $-10.50 \%$ and $-11.69 \%$, respectively whereas the second half of the period gathers a bull market. It is also remarkable, the higher volatility during the bear period, $22.34 \%$ and $18.74 \%$ as opposed to $9.19 \%$ and $8.23 \%$ in the bull market. Finally, we highlight that pension plans' volatility measured by the standard deviation is between the volatility of the equity and bond benchmark as expected given that our samples consist of balanced pension schemes. 
To test Sharpe's (1992) model in our samples and to determine the average exposure of Spanish balanced plans to the different indices, we create an equallyweighted portfolio by averaging all fund returns during a given month. Results from the estimation are shown in Table 3.

\section{Table 3. Portfolio results of Sharpe's (1992) style analysis.}

The top row reports the figures of Spanish balanced pension plans investing in Euro Zone equities whereas the bottom row reports the figures for Spanish balanced pension plans investing in World equities during the entire period analysed, 2001-2007. Each row contains the results of the return-based style analyses proposed by Sharpe (1992) for the equally-weighted portfolio.

\begin{tabular}{lcccccc}
\hline & $\boldsymbol{\beta}_{0}$ & $\begin{array}{c}\boldsymbol{\beta}_{1} \\
(\text { Equities })\end{array}$ & $\begin{array}{c}\boldsymbol{\beta}_{2} \\
\text { (Fixed-Income) }\end{array}$ & $\begin{array}{c}\boldsymbol{\beta}_{3} \\
(\text { Cash })\end{array}$ & $\boldsymbol{R}^{2}$ & $\boldsymbol{A d j} \boldsymbol{R}^{2}$ \\
\hline Euro Zone equities & 0.0002 & 0.4609 & 0.2221 & 0.3170 & $89.40 \%$ & $89.00 \%$ \\
\hline World equities & 0.0013 & 0.4913 & 0.1994 & 0.3094 & $90.60 \%$ & $90.25 \%$ \\
\hline
\end{tabular}

Based on the results of Table 3, we can, once more, conclude the importance of both equities and bonds in our sample. A slightly higher adjusted $\mathrm{R}^{2}$ is observed when analyzing World equities as well as a higher figure of the value added by active managers in comparison to that obtained by Euro zone managers. ${ }^{12}$

\section{PERFORMANCE EVALUATION MODELS AND EMPIRICAL RESULTS}

\subsection{Performance measured by Alpha}

The financial literature on the performance of collective investment portfolios usually provides evidence of negative alphas, on average, once adjusted for fees (see e.g. Jensen, 1968). In order to test this finding in our sample of balanced personal pension plans, we assume that the monthly pension plan returns can be characterized by a

\footnotetext{
${ }^{12}$ In Appendix 2 we show that the influence of a look-ahead bias is small. Therefore, the requirement of a minimum time period to be included in the sample does not distort our findings.
} 
generalization of the single factor model proposed by Jensen (1968). The model is expressed as follows:

$$
r_{p, t}^{e}=\alpha_{p}+\beta_{p, t}^{E} r_{e, t}^{e}+\beta_{p, t}^{B} r_{b, t}^{e}+\varepsilon_{p, t}
$$

where $r_{p, t}^{e}$ denotes the excess return over the risk-free rate ${ }^{13}$ of the pension plan $p$ in period $t, r_{e, t}^{e}\left(r_{b, t}^{e}\right)$ denotes the excess return of the equity market (bond market) over the same period, $\beta^{E}\left(\beta^{B}\right)$ denotes the sensitivity of the portfolio return to the stock market (bond market) movements, $\alpha_{p}$ denotes the selectivity return of the manager of portfolio $p$ and $\varepsilon_{p, t}$ denotes the error term of the model.

The main issue is to test whether this model effectively represents the returns of balanced pension plans. To check the effectiveness of this model, we start our investigation by estimating equation 1 for each of the 94 and 45 pension plans from our samples in order to do inferences for individual plans. ${ }^{14}$ Summary statistics of the estimation results by using the ordinary least square method are shown in Table 4.

Several findings are observed from this table. First, the model proposed is appropriate since it explains $73 \%$ and $72 \%$ of the variation in returns when using individual pension plans as indicated by the high $R^{2}$ coefficient obtained. Second, the results show that the average equity market exposure is 0.47 and 0.50 , respectively. This result is consistent with the limits stated by the investment vocation. Third, the exposure to the bond market is also significant, being, on average, 0.25 and 0.18 . Therefore, the results suggest the importance of modelling the bond portion of the balanced plans. This is a finding similar to that obtained by previous studies examining balanced portfolios, such as Comer (2006) and Rodriguez (2008).

\footnotetext{
${ }^{13}$ 1-day Spanish Treasury Bill Repos is the benchmark used as a risk-free rate.

${ }^{14}$ In Appendix 2 we show the equally-weighted portfolio without look-ahead bias and observe that results are qualitatively the same.
} 


\section{Table 4. Estimation results of equity and bond exposures}

The estimation results of Equation 1 are displayed in this table, where the alpha parameter is expressed in annual terms. The table is divided in two panels. Panel A reports the results for the sample of pension plans investing in Euro Zone Equities whereas Panel B reports the results for those portfolios investing in World Equities. Moreover, each panel contains two sections. The upper side of each panel shows the summary results obtained when analysing pension plans individually whereas the bottom side of the panel shows the results obtained when analysing equally-weighted portfolios. The heteroskedasticity and autocorrelation consistent standard error test as described by Newey and West (1987) has been used in order to calculate the significance levels.

\begin{tabular}{|c|c|c|c|c|}
\hline Panel A: Euro Zone plans & Annual $\alpha$ & $\beta^{E}$ & $\beta^{B}$ & $\mathbf{R}^{2}$ \\
\hline Average & $-0.58 \%$ & 0.47 & 0.25 & 0.73 \\
\hline Median & $-1.04 \%$ & 0.45 & 0.21 & 0.76 \\
\hline Positive & 26 & 94 & 89 & \\
\hline of which significant at $5 \%$ & 4 & 94 & 33 & \\
\hline Negative & 68 & 0 & 5 & \\
\hline of which significant at $5 \%$ & 13 & 0 & 0 & \\
\hline Equally-weighted portfolio & $-0.61 \%$ & 0.47 & 0.22 & 0.87 \\
\hline p-value & $(0.51)$ & $(0.00)$ & $(0.14)$ & \\
\hline Panel B: World plans & Annual $\alpha$ & $\beta^{E}$ & $\beta^{B}$ & $\mathbf{R}^{2}$ \\
\hline Average & $1.46 \%$ & 0.50 & 0.18 & 0.72 \\
\hline Median & $0.92 \%$ & 0.50 & 0.18 & 0.75 \\
\hline Positive & 30 & 45 & 34 & \\
\hline of which significant at $5 \%$ & 9 & 45 & 16 & \\
\hline Negative & 15 & 0 & 11 & \\
\hline of which significant at $5 \%$ & 0 & 0 & 0 & \\
\hline Equally-weighted portfolio & $0.61 \%$ & 0.49 & 0.22 & 0.89 \\
\hline p-value & $(0.58)$ & $(0.00)$ & $(0.04)$ & \\
\hline
\end{tabular}

However, it is also important to notice the difference between the average alpha achieved by Spanish balanced pension plans depending on the investment vocation. As expected by the descriptive statistics of Table 2, the average alpha of Euro Zone portfolios is negative $(-0.58 \%)$ while this parameter in World pension plans is positive $(1.46 \%)$.

The difference in alphas between the two samples can also be observed in Figure 1, where the distribution of the stock-picking skill of the pension plans in our samples is displayed. Overall, the figure associated to Euro Zone plans indicates that 
the selectivity skill is concentrated in the negative part of the figure, with 68 out of 94 plans having a negative estimate for alpha. Furthermore, of the 17 significant alphas, 13 are negative. On the contrary, the stock picking skill of World plans is concentrated in the positive part of the figure, with 30 out of 45 plans having a positive estimate. Moreover, no negative and statistically significant alphas are observed.

Previous studies finding negative alphas interpreted them as an indicator of poor performance. For that reason, from our results based on a generalization of the single factor model proposed by Jensen (1968), we can conclude that the Spanish pension managers investing in Euro Zone equities are not adding value to the passive market index as opposed to pension managers investing in World equities. Moreover, the dispersion in the manager selectivity indicates the risk for investors from picking the right or wrong manager, all other things equal.

\section{Figure 1 - Histogram of selectivity skill: The generalization of the single factor model proposed by Jensen (1968)}

This figure exhibits the histogram of the selectivity skill according to the estimation of Equation 1 for each pension plan. The left side of the figure shows the histogram for those pension plans investing in Euro Zone Equities whereas the histogram of the portfolios investing in World equities is displayed in the right side of the figure.
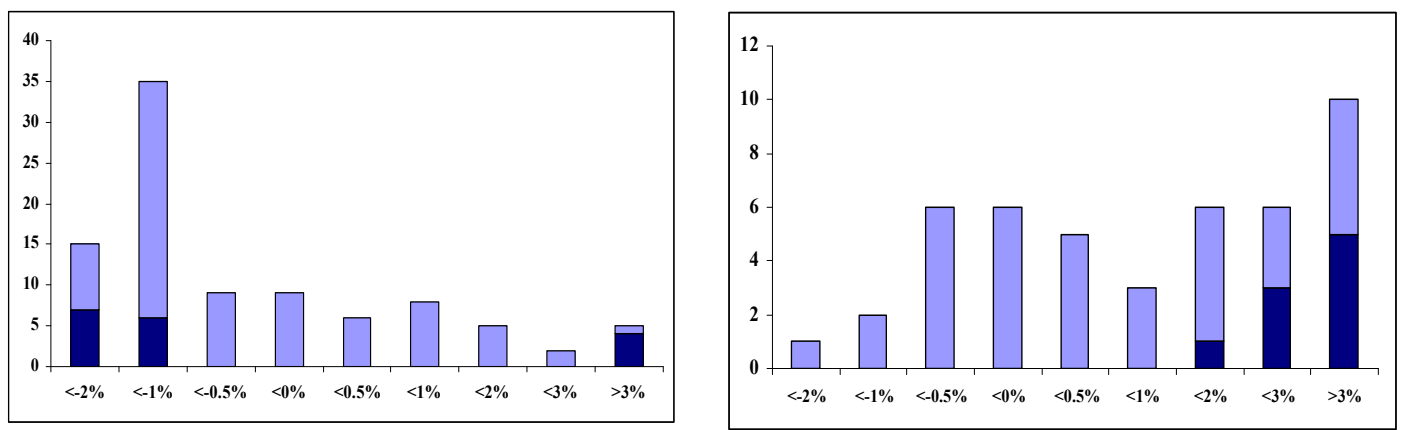


\subsection{Performance considering market timing skills}

The selectivity measure (alpha) from equation 1 does not take into account the potential market timing that Spanish pension managers can have by moving in and out the market, or buying stocks with high and low beta depending on the market returns. Therefore, we go a step further by analysing the timing abilities considering a multifactor extension of the traditional evaluation model proposed by Treynor and Mazuy (1966).

In particular, this model evaluates the relation between a fund portfolio's sensitivity coefficient to the market portfolio and the actual return on the market. A positive relationship indicates that the fund manager correctly forecasts equity market movements and adjusts the portfolio composition accordingly. In other words, the fund manager possesses skill in timing the market when the relation between the market sensitivity and the realized market return is significantly positive.

This traditional model analyzes funds as whether they are composed of only stocks and Treasury Bills and evaluates the performance by focusing on the choice between stocks and cash. As a result, the model ignores the portion of the portfolios of balanced pension plans that is invested in bonds, although it is well-known that to properly measure the timing skill, a model should include all assets in which the portfolio invests and the timing coefficients for each of these assets. In this sense, Lehmann and Modest (1987) provide the foundation for a multifactor extension of the quadratic regression approach. They illustrate that a multifactor extension of the Treynor and Mazuy model would include quadratic terms and cross-terms of all the assets.

Due to the importance of the equity and bond exposures and the variability of those exposures over time in our two samples of balanced pension plans, as 
demonstrated in Tables 1 and 3, we extend the traditional performance evaluation model to check both types of timing skills, equity and bond market timing. However, we exclude the cross-terms in the interest of maintaining a parsimonious timing model.

This analysis supposes an original and innovative approach since the majority of the studies in the financial literature only focus their attention on the equity market timing. Some exceptions, as we have previously mentioned, are the investigations carried out by Comer (2006), Rodriguez (2008) and Swinkels and Tjong-a-Tjoe (2008). The first studies apply a multifactor version of the Treynor and Mazuy model whereas the latter examines the style timing along with the equity market timing.

Using the two-factor model of equation 1, we can derive an appropriate multifactor version of Treynor and Mazuy (1966) model to measure the timing abilities of Spanish balanced pension plans. This multifactor model can be described as follows ${ }^{15}$ :

$$
r_{p, t}^{e}=\alpha_{p}+\bar{\beta}^{E} r_{e, t}^{e}+\bar{\beta}^{B} r_{b, t}^{e}+\gamma_{E}\left(r_{e, t}^{e}\right)^{2}+\gamma_{B}\left(r_{b, t}^{e}\right)^{2}+\varepsilon_{p, t}
$$

where $\alpha_{p}$ the selectivity skill, $\bar{\beta}^{E}\left(\bar{\beta}^{B}\right)$ is the average exposure to the equity (bond) market, $\gamma_{E}\left(\gamma_{B}\right)$ is the coefficient of the equity (bond) market timing and $\varepsilon_{p, t}$ is the error term.

The estimation results from the multifactor version of Treynor and Mazuy (1966) market timing model are summarized in Table 5. Panels A and B show that the majority of the pension plans present a positive alpha. Specifically, in the Euro Zone sample, a total of 64 out of 94 pension plans present a positive alpha while in the World sample, this figure is 35 out of 45 . Taking into account the level of

\footnotetext{
${ }^{15}$ Appendix 1 shows a more complex specification of the multifactor version of Treynor and Mazuy (1966) model obtaining similar results.
} 
significance, we observe a clear difference between both datasets since only a $6.4 \%$ of the Spanish balanced plans investing in Euro Zone equities has a significant positive stock picking ability while this percentage rise to $24.4 \%$ in the world sample. These differences in the alphas for both samples are consistent with the findings in Figure 1.

\section{Table 5. Results of Timing and Selectivity: The multifactor extension of Treynor and Mazuy Model}

The table is divided in two panels: Panel A and Panel B. Panel A reports the results of the multifactor extension of Treynor and Mazuy (1966) model as expressed in equation 2 as well as the distribution of the distribution of the different parameters, for our sample of Spanish balanced personal pension schemes investing in Euro Zone equities over the period 2000-2007 whereas Panel B reports the results of pension schemes investing in World equities. Moreover, each panel contains two sections. The upper side of each panel shows the summary results obtained when analysing pension plans individually whereas the bottom side of the panel shows the results obtained when analysing equally-weighted portfolios. The heteroskedasticity and autocorrelation consistent standard error test as described by Newey and West (1987) has been used in order to calculate the significance levels.

\begin{tabular}{lccccc}
\hline Panel A: Euro Zone Pension Plans & $\boldsymbol{\alpha}$ & $\boldsymbol{\beta}^{\boldsymbol{E}}$ & $\gamma_{\mathrm{E}}$ & $\boldsymbol{\beta}^{\boldsymbol{B}}$ & $\gamma_{\mathrm{B}}$ \\
\hline Average & $1.09 \%$ & 0.47 & -0.08 & 0.27 & -21.07 \\
Median & $1.53 \%$ & 0.44 & -0.12 & 0.25 & -27.21 \\
Positive & 64 & 94 & 32 & 90 & 17 \\
$\quad$ of which significant at 5\% & 6 & 94 & - & 26 & - \\
Negative & 30 & - & 62 & 4 & 77 \\
$\quad$ of which significant at 5\% & 3 & - & 4 & - & 29 \\
\hline Equally-weighted portfolio & $1.07 \%$ & 0.46 & 0.02 & 0.25 & -24.44 \\
p-values & $(0.49)$ & 0.00 & 0.92 & 0.06 & 0.01 \\
\hline Panel B: World Pension Plans & $\boldsymbol{\alpha}$ & $\boldsymbol{\beta}^{\boldsymbol{E}}$ & $\gamma_{\mathrm{E}}$ & $\boldsymbol{\beta}^{\boldsymbol{B}}$ & \multicolumn{1}{c}{$\boldsymbol{\gamma}_{\mathrm{B}}$} \\
\hline Average & $1.81 \%$ & 0.5 & -0.68 & 0.17 & 6.12 \\
Median & $1.39 \%$ & 0.46 & -0.63 & 0.15 & 4.30 \\
Positive & 35 & 45 & 12 & 37 & 26 \\
$\quad$ of which significant at 5\% & 11 & 45 & - & 7 & 8 \\
Negative & 10 & - & 33 & 8 & 19 \\
$\quad$ of which significant at 5\% & 0 & - & 16 & - & 2 \\
\hline Equally-weighted portfolio & $0.61 \%$ & 0.48 & -0.55 & 0.21 & 18.52 \\
p-values & $(0.77)$ & $(0.00)$ & $(0.11)$ & $(0.04)$ & $(0.04)$ \\
\hline
\end{tabular}


Regarding the timing coefficients, in Panel A, an average negative coefficient for both, equity and bond market timing can be observed when focusing the attention on individual results. Specifically, 4 pension plans show a significantly negative equity timing ability. These figures are even worse when we check the bond market timing, where there are 29 portfolios (31\% of the sample) showing a significantly negative bond timing skill. This negative and statistically significant bond timing ability reported by Euro zone pension plans individually is reinforced by the aggregate results.

On the other hand, results of Panel B show an average negative equity timing coefficient, being statistically significant in 16 portfolios ( $36 \%$ of the sample). It is also important to notice that this parameter is more negative in the world dataset than in Euro Zone pension plans. However, unlike the result of Euro Zone pension plans, world portfolios present an average positive bond timing parameter, being positive statistically significant in 8 pension plans as well as for the equally-weighted portfolio. $^{16}$

Figure 2 displays the distribution of the selectivity skill of the pension schemes included in our two samples. Overall, this figure indicates that the selectivity skill is concentrated in the positive part of the figure regardless of the investment vocation examined. However, it is important to remember that gross returns have been used in our paper. In this respect, the average positive alphas are $1.09 \%$ and $1.81 \%$ per year while the average management and custodial fee for these portfolios is $1.90 \%$ for Euro Zone portfolios and $1.80 \%$ for world portfolios. It would be tempting to conclude that these pension plans are therefore not adding any value to the Spanish pension investors. However, one should bear into mind that the indices used in this

\footnotetext{
${ }^{16}$ In Appendix 2 we show the equally-weighted portfolio without look-ahead bias and observe that results are qualitatively the same.
} 
research are not available to individual investors at zero costs. ${ }^{17}$ Boney et al. (2009) also justified the survival of the funds of their sample despite their negative performance due to the value investors place on the portfolio diversification benefits.

\section{Figure 2. Histogram of the selectivity skill: The multifactor extension of Treynor and Mazuy Model}

This figure exhibits the histogram of the selectivity skill when the multifactor extension of the Treynor and Mazuy model is applied. The left side of the figure shows the histogram for those pension plans investing in Euro Zone Equities whereas the histogram of the portfolios investing in World equities is displayed in the right side of the figure.
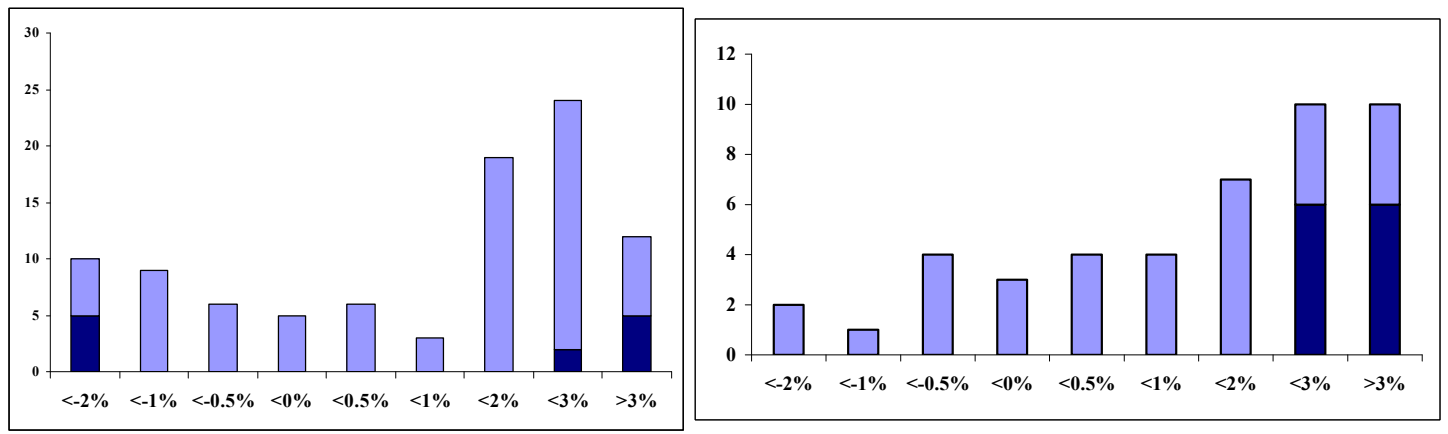

It is also important to notice that the consideration of the timing skills has lead to different conclusions about the selectivity ability of Euro Zone pension managers. We provide evidence that the market timing model offers more information about the management skills than the augmented version of the Jensen (1968) model since the latter does not take into account other abilities differ from stock picking. In this sense, the usual negative alphas provided by the Jensen equation are mainly due to the lack of market timing abilities. Notwithstanding, we detect stock picking skills as can be observed from the positive alpha coefficients in the market timing model.

Figures 3 and 4 display the distribution of the equity and bond timing return of our two samples. Thus, we can decompose the return added or subtracted by the three

\footnotetext{
${ }^{17}$ Passive index funds or Exchange Traded Funds seem to underperform the indices used by $0.50 \%$ $1.00 \%$ after all costs are taken into account.
} 
different management skills. In this sense, Figure 5 exhibits the distribution of the total return provided by the three different skills: selectivity, equity timing and bond timing.

Figure 3. Histogram of the equity timing return: The multifactor extension of Treynor and Mazuy Model

This figure exhibits the histogram of the equity timing return when the multifactor extension of the Treynor and Mazuy model is applied. The left side of the figure shows the histogram for those pension plans investing in Euro Zone Equities whereas the histogram of the portfolios investing in World equities is displayed in the right side of the figure.
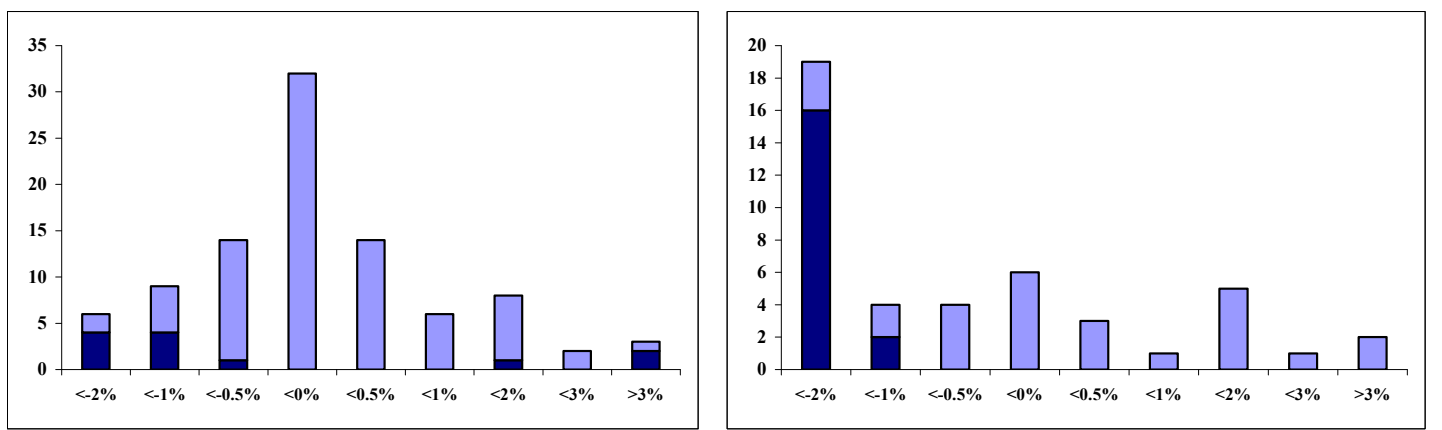

Figure 4. Histogram of the bond timing return: The multifactor extension of Treynor and Mazuy Model.

This figure exhibits the histogram of the bond timing return when the multifactor extension of the Treynor and Mazuy model is applied. The left side of the figure shows the histogram for those pension plans investing in Euro Zone Equities whereas the histogram of the portfolios investing in World equities is displayed in the right side of the figure.
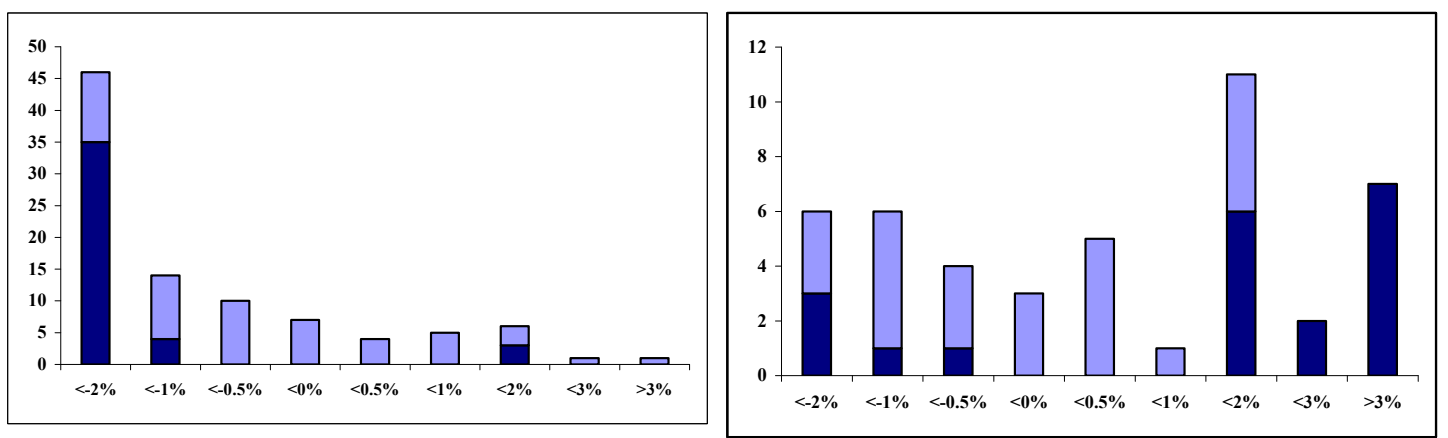
Before concluding the paper, let us show an example to illustrate the potential magnitudes of the different management skills. Suppose a pension scheme that presents the average parameters of the Euro Zone sample: $\alpha=0.09 \%$ per month, $\beta^{\mathrm{E}}=$ $0.47, \beta^{\mathrm{B}}=0.27, \gamma^{\mathrm{E}}=-0.08$ and $\gamma^{\mathrm{B}}=-21.07$, being the average excess return of the equity market $0.5 \%$ per month and the average excess return of the bond market $0.1 \%$ per month as we can observed in the sample. The return of the different management skills of this pension plan equals:

Management skills return $=0.09 \%+(-0.08 * 0.25 \%)+(-21.07 * 0.01 \%)=$

$$
0.09 \%+(-0.02 \%)+(-0.21 \%)=-0.14 \%
$$

In this example, the most important factor in the return subtracted by the manager is the negative bond market timing. The management skills subtract a monthly return of $-0.14 \%$ before considering the management and custodial fees. Now suppose the average parameters of the World sample: $\alpha=0.15 \%$ per month, $\beta^{E}=0.50, \beta^{B}=0.17, \gamma^{E}=-0.68$ and $\gamma^{B}=6.12$. The return of the different management skills of this pension plan equals:

Management skills return $=0.15 \%+(-0.68 * 0.25 \%)+(6.12 * 0.01 \%)=$

$$
0.15 \%+(-0.17 \%)+(0.06 \%)=0.04 \%
$$

In this second example, we can see that the management skills added a return of $0.04 \%$ and we are able to check that the most important management skill is the stock picking.

From Figure 5 we observe that for the Euro Zone pension plans the total skill provided by the pension fund manager is mostly negative. The manager skill of World pension plans is also mostly negative, but we also observe that 10 pension plans have a management skill above 3\% per annum. Based on these results, we conclude that the management skill in World pension plans is higher than that in Euro Zone pension 
plans. This could be related to the larger opportunity set for these managers as they may invest in global equity and bonds markets.

Figure 5. Histogram of the total return added by the different management

\section{skills: The multifactor extension of Treynor and Mazuy Model.}

This figure exhibits the histogram of the total return added by the different management skills (selectivity, equity timing and bond timing) when the multifactor extension of the Treynor and Mazuy model is applied. The left side of the figure shows the histogram for those pension plans investing in Euro Zone Equities whereas the histogram of the portfolios investing in World equities is displayed in the right side of the figure.

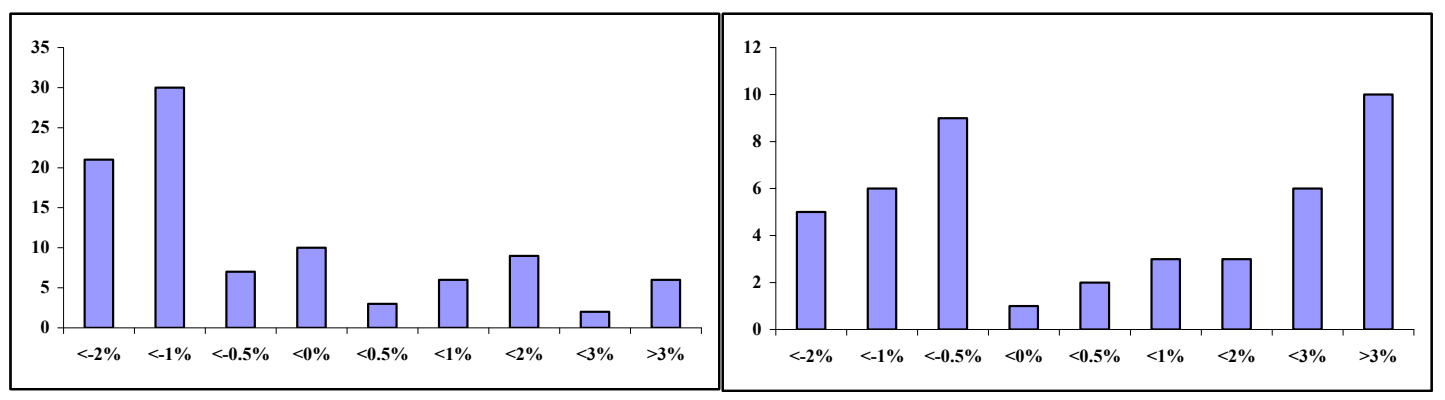

\section{CONCLUSIONS}

This paper empirically examines the management skills of Spanish balanced pension plans that invest in Euro Zone and World equities during the period 2000-2007. In order to achieve this goal, we have used a multifactor extension of Treynor and Mazuy (1966) model given that traditional market timing models are not suitable to analyse balanced portfolios. As far as we know, we are among the first to apply this novel multifactor model specification, which allows us to decompose the pension fund manager's skills in three different components: selectivity, equity market timing and bond market timing.

Our empirical results suggest that the stock picking ability of pension plans is on average positive, with $1.1 \%$ and $1.8 \%$ per annum for Euro Zone and World pension plans, respectively. Since this analysis is based on gross returns, management fees of 
approximately $1.8 \%$ per annum still have to be subtracted for real-life investor returns. Spanish pension plans are on average not able to time equity markets although positive bond timing is observed in World portfolios.

Previous literature provides evidence that the use of daily data improves detecting timing ability that we document considering monthly information. Therefore, a next step for future research may be to compare our results to those obtained by using daily data, but currently this data is not available. 


\section{REFERENCES}

Andreu, L., Ferruz, L., Vicente, L., 2009. The Importance of asset allocation in Spanish equity pension plans. Journal of Pension Economics and Finance, Forthcoming.

Bollen, N.P.B., and Busse, J.A., 2001. On the timing ability of mutual fund managers. The Journal of Finance, 56(3), 1075-1094.

Boney, V., Comer, G., and Kelly, L., 2009. Timing the investment grade securities market: Evidence from high quality bond funds. Journal of Empirical Finance, $16,55-69$.

Brinson, G.P., Hood, L.R., and Beebower, G.L., 1986. Determinants of portfolio performance. Financial Analysts Journal, 42(4), 39-44.

Brinson, G.P., Singer, B.D., and Beebower, G.L., 1991. Determinants of portfolio performance II: An update. Financial Analysts Journal, 47(3), 40-48.

Comer, G., 2006. Hybrid mutual funds and market timing performance. The Journal of Business, 79(2), 771-797.

Doncel, L.M., Grau-Carles, P., and Sainz, J., 2009, “On the long-term behavior of mutual fund returns", Quantitative Finance, 9(6), 653-660.

Edelen, R., 1999. Investor flows and the assessed performance of open-ended mutual funds. Journal of Financial Economics, 53, 439-466.

Ferruz, L., and Vargas, M., 2007. A bet on passive investment strategies. The International Journal of Applied Economics and Finance, 1(2), 67-78. 
Ferruz, L., Vargas, M., and Sarto, J.L., 2006. Evaluation of performance and conditional information: The case of spanish mutual funds. Applied Financial Economics, 16(11), 803-817.

Ferson, W.E., and Schadt, R.W., 1996. Measuring fund strategy and performance in changing economic conditions. The Journal of Finance, 51(2), 425-461.

Glassman, D.A., and Riddick, L.A., 2006. Market timing by global fund managers. Journal of International Money and Finance, 25(7), 1029-1050.

Jensen, M., 1968. The performance of mutual funds in the period 1945-1964. Journal of Finance, 23(2), 389-416.

Jiang, G.J., Yao, T., and Yu, T., 2007. Do mutual funds time the market? evidence from portfolio holdings. Journal of Financial Economics, 86(3), 724-758.

Lehmann, B.N., and Modest, D.M., 1987. Mutual fund performance evaluation: A comparison of benchmarks and benchmark comparisons. The Journal of Finance, 42(2), 233-265.

Matallín, J. C. 2006. Seasonality, market timing and performance: Amongs benchmarks and mutual fund evaluation. Journal of Business Finance and Accounting, 33(9-10), 1484-1507.

Newey, W.K., and West, K.D., 1987. A simple, positive semi-definite, heteroskedasticity and autocorrelation consistent covariance matrix. Econometrica (1986-1998), 55(3), 703-708.

Pástor, L., and Stambaugh, R., 2002. Mutual fund performance and seemingly unrelated assets. Journal of Financial Economics, 63(3), 315-349. 
Rodríguez, J., 2008. Market timing: A global endeavor. Journal of International Financial Markets, Institutions and Money, Forthcoming.

Sharpe, W.F., 1992. Asset allocation: Management style and performance measurement. Journal of Portfolio Management, 18(2), 7-19.

Swinkels, L., and Tjong-A-Tjoe, L., 2007. Can mutual funds time investment styles? Journal of Asset Management, 8(2), 123-132.

Treynor, J.L., and Mazuy, K., 1966. Can mutual funds outguess the market? Harvard Business Review, 44, 131-136.

Warther, V. A., 1995. Aggregate mutual fund flows and security returns. Journal of Financial Economics, 39, 209-235.

Wermers, R., and Moskowitz, T.J., 2000. Mutual fund performance: An empirical decomposition into stock-picking talent, style, transactions costs, and expenses. The Journal of Finance, 55(4), 1655-1703. 


\section{APPENDIX 1: Another multifactor version of Treynor and Mazuy (1966) model}

Although not reported, empirical results are virtually identical when we considered another more complex specification of the multifactorial version of the model proposed by Treynor and Mazuy (1966). In this new specification we one a step further including not only the bond timing to the traditional models but also the choice between stocks and bonds apart from the choice between stocks and cash. This alternative multifactorial model can be derived as follows:

$$
r_{p, t}^{e}=\alpha_{p}+\beta_{p, t+1}^{E} r_{e, t}^{e}+\beta_{p, t+1}^{B} r_{b, t}^{e}+\varepsilon_{p, t}
$$

As we have previously mentioned, this model states that the market exposure is linearly related to the excess realized returns of the market. Therefore, the dynamic processes for the equity and bond market exposures are described by the following expressions:

$$
\begin{aligned}
& \beta^{E}{ }_{t+1}=\bar{\beta}^{E}+\gamma_{1}\left(R_{e, t+1}-R_{f}\right)+\gamma_{2}\left(R_{e, t+1}-R_{b, t+1}\right)+\eta_{t+1} \\
& \beta^{B}{ }_{t+1}=\bar{\beta}^{B}+\gamma_{3}\left(R_{b, t+1}-R_{f}\right)+\gamma_{4}\left(R_{b, t+1}-R_{e, t+1}\right)+\eta_{t+1}
\end{aligned}
$$

Replacing equations 5 and 6 into equation 4, we obtain the alternative multifactorial version of Treynor and Mazuy (1966).

$$
\begin{aligned}
r_{p, t}^{e}= & \alpha_{p}+\bar{\beta}^{E} r_{e, t}^{e}+\bar{\beta}^{B} r_{b, t}^{e}+\gamma_{1}\left(r_{e, t}^{e}\right)^{2}+\gamma_{2}\left(r_{e, t}^{e}\right)^{2}+\gamma_{3}\left(r_{b, t}^{e}\right)^{2}+ \\
& \gamma_{4}\left(r_{b, t}^{e}\right)^{2}-\gamma_{2}\left(r_{e, t}^{e} * r_{b, t}^{e}\right)-\gamma_{4}\left(r_{e, t}^{e} * r_{b, t}^{e}\right)+\varepsilon_{p, t}
\end{aligned}
$$

This expression can also be rewritten as:

$$
\begin{aligned}
r_{p, t}^{e}= & \alpha_{p}+\bar{\beta}^{E} r_{e, t}^{e}+\bar{\beta}^{B} r_{b, t}^{e}+\left(\gamma_{1}+\gamma_{2}\right)\left(r_{e, t}^{e}\right)^{2}+\left(\gamma_{3}+\gamma_{4}\right)\left(r_{b, t}^{e}\right)^{2}+ \\
& \left(-\gamma_{2}-\gamma_{4}\right)\left(r_{e, t}^{e} * r_{b, t}^{e}\right)+\varepsilon_{p, t}
\end{aligned}
$$




\section{APPENDIX 2: Evaluation of the impact of look-ahead bias}

This appendix contains comparisons of the sample of equally-weighted pension plans mentioned in the main text (with look-ahead bias) with the sample of equallyweighted pension plans without look-ahead bias.

\section{Table A2.1: Comparison of Table 3 with the sample without look-ahead bias}

The table is divided into two panels. Panel A reports the figures of Spanish balanced pension plans investing in Euro Zone equities whereas Panel B reports the figures for Spanish balanced pension plans investing in World equities during the entire period analysed, 2001-2007. Each panel contains the results of the return-based style analyses proposed by Sharpe (1992) for the equally-weighted portfolio including all the pension plans existing in each period (the unbiased equally-weighted portfolio) as well as the equally-weighted portfolio including those pension plans with at least 36 observations (the equally-weighted portfolio with look-ahead bias).

\begin{tabular}{|c|c|c|c|c|c|c|}
\hline $\begin{array}{l}\text { Panel A: } \\
\text { Euro Zone equities }\end{array}$ & $\beta_{0}$ & $\begin{array}{c}\beta_{1} \\
(M S C I E m u)\end{array}$ & $\begin{array}{c}\beta_{2} \\
\text { (Fixed-Income) }\end{array}$ & $\begin{array}{c}\beta_{3} \\
\text { (Cash) }\end{array}$ & $R^{2}$ & $\operatorname{Adj.} R^{2}$ \\
\hline Unbiased Portfolio & 0.0003 & 0.4532 & 0.2245 & 0.3223 & $89.30 \%$ & $88.90 \%$ \\
\hline $\begin{array}{l}\text { Portfolio with } \\
\text { Look-Ahead bias }\end{array}$ & 0.0002 & 0.4609 & 0.2221 & 0.3170 & $89.40 \%$ & $89.00 \%$ \\
\hline $\begin{array}{l}\text { Panel B: } \\
\text { World equities }\end{array}$ & $\beta_{0}$ & $\begin{array}{c}\beta_{1} \\
\text { (MSCI World) }\end{array}$ & $\begin{array}{c}\beta_{2} \\
\text { (Fixed-Income) }\end{array}$ & $\begin{array}{c}\beta_{3} \\
\text { (Cash) }\end{array}$ & $R^{2}$ & $\operatorname{Adj.} R^{2}$ \\
\hline Unbiased Portfolio & 0.0013 & 0.4587 & 0.1841 & 0.3572 & $90.40 \%$ & $90.04 \%$ \\
\hline $\begin{array}{l}\text { Portfolio with } \\
\text { Look-Ahead bias }\end{array}$ & 0.0013 & 0.4913 & 0.1994 & 0.3094 & $90.60 \%$ & $90.25 \%$ \\
\hline
\end{tabular}


Table A2.2: Comparison of results of Table 4 with the sample without look-ahead bias

The estimation results of Equation 1 are displayed in this table, where the alpha parameter is expressed in annual terms. The table is divided in two panels. Panel A reports the results for the sample of pension plans investing in Euro Zone Equities whereas Panel B reports the results for those portfolios investing in World Equities. Moreover, each panel contains two sections. The upper side of each panel shows the summary results obtained when analysing pension plans individually whereas the bottom side of the panel shows the results obtained when analysing equally-weighted portfolios. The heteroskedasticity and autocorrelation consistent standard error test as described by Newey and West (1987) has been used in order to calculate the significance levels.

\begin{tabular}{lcccc}
\hline Panel A: Euro Zone Pension Plans & Annual $\boldsymbol{\alpha}$ & $\boldsymbol{\beta}^{\mathbf{E}}$ & $\boldsymbol{\beta}^{\mathbf{B}}$ & $\mathbf{R}^{\mathbf{2}}$ \\
\hline Unbiased portfolio & $-0.59 \%$ & 0.46 & 0.22 & 0.87 \\
p-value & $(0.51)$ & $(0.00)$ & $(0.14)$ & \\
Look-ahead biased portfolio & $-0.61 \%$ & 0.47 & 0.22 & 0.87 \\
p-value & $(0.51)$ & $(0.00)$ & $(0.14)$ & \\
\hline Panel B: World Pension Plans & Annual $\boldsymbol{\alpha}$ & $\boldsymbol{\beta}^{\mathbf{E}}$ & $\boldsymbol{\beta}^{\mathbf{B}}$ & $\mathbf{R}^{\mathbf{2}}$ \\
\hline Unbiased portfolio & $0.61 \%$ & 0.46 & 0.21 & 0.88 \\
p-value & $(0.55)$ & $(0.00)$ & $(0.03)$ & \\
Look-ahead biased portfolio & $0.61 \%$ & 0.49 & 0.22 & 0.89 \\
p-value & $(0.58)$ & $(0.00)$ & $(0.04)$ & \\
\hline
\end{tabular}




\section{Table A2.3: Comparison of results of Table 5 with the sample without look-ahead bias}

The table is divided in two panels: Panel A and Panel B. Panel A reports the results of the multifactor extension of Treynor and Mazuy (1966) model as expressed in equation 2 as well as the distribution of the distribution of the different parameters, for our sample of Spanish balanced personal pension schemes investing in Euro Zone equities over the period 2000-2007 whereas Panel B reports the results of pension schemes investing in World equities. Moreover, each panel contains two sections. The upper side of each panel shows the summary results obtained when analysing pension plans individually whereas the bottom side of the panel shows the results obtained when analysing equally-weighted portfolios. The heteroskedasticity and autocorrelation consistent standard error test as described by Newey and West (1987) has been used in order to calculate the significance levels.

\begin{tabular}{lccccc}
\hline Panel A: Euro Zone Pension plans & $\boldsymbol{\alpha}$ & $\boldsymbol{\beta}^{E}$ & $\gamma_{\mathrm{E}}$ & $\boldsymbol{\beta}^{\boldsymbol{B}}$ & $\gamma_{\mathbf{B}}$ \\
\hline Unbiased portfolio & $1.06 \%$ & 0.46 & 0.03 & 0.25 & -24.41 \\
p-values & $(0.49)$ & $(0.00)$ & $(0.88)$ & $(0.06)$ & $(0.01)$ \\
Look-ahead biased portfolio & $1.07 \%$ & 0.46 & 0.02 & 0.25 & -24.44 \\
p-values & $(0.49)$ & 0.00 & 0.92 & 0.06 & 0.01 \\
\hline \hline Panel B: World Pension Plans & $\boldsymbol{\alpha}$ & $\boldsymbol{\beta}^{\boldsymbol{E}}$ & $\gamma_{\mathrm{E}}$ & $\boldsymbol{\beta}^{\boldsymbol{\beta}}$ & $\gamma_{\mathbf{B}}$ \\
\hline Unbiased portfolio & $0.61 \%$ & 0.45 & -0.47 & 0.20 & 13.28 \\
p-values & $(0.62)$ & $(0.00)$ & $(0.24)$ & $(0.03)$ & $(0.15)$ \\
Look-ahead biased portfolio & $0.61 \%$ & 0.48 & -0.55 & 0.21 & 18.52 \\
p-values & $(0.77)$ & $(0.00)$ & $(0.11)$ & $(0.04)$ & $(0.04)$ \\
\hline
\end{tabular}

